\section{Immunotoxicity of silver nanoparticles in blue mussel (Mytilus edulis)}

\author{
C. Côté, ${ }^{1-3}$ K. Lemarchand, ${ }^{4}$ I. Desbiens, ${ }^{4}$ \\ M. Barthes, ${ }^{4}$ K. Osterheld, ${ }^{4}$ M. Millour, ${ }^{4}$ \\ É. Pelletier, ${ }^{4}$ M. Fournier, ${ }^{1-4}$ \\ P. Brousseau ${ }^{1-4}$
}

${ }^{1}$ Parc de la rivière Mitis, Ste-Flavie; Institut National de la Recherche

Scientifique-Institut-Armand-Frappier

(INRS-IAF), Laval; ' ${ }^{U}$ niversité du Québec

à Rimouski; ${ }^{4}$ Institut des Sciences de la

mer de Rimouski (ISMER), QUE, Canada

\section{Introduction}

With the rapidly expanding area of nanotechnology over the last few years, the use of nanomaterials has pervaded many consumer products..$^{1-3}$ Nanomaterials can be found in various areas such as health care and consumer products like cosmetics, food and clothing. ${ }^{3-5}$ Among all the nanoparticles produced each year, silver nanoparticles are the fastest growing nanocompounds, mainly for their antimicrobial and anti-odor properties., ${ }^{3,4}$ Nanosilver particles have been incorporated in many products ranging from pool cleaning systems, odorresistant textiles, cosmetics, electronics as well as general household appliances. ${ }^{3-}$

The rapidly growing field of nanotechnology brings concern on the toxicity and outcomes from environmental exposure of marine invertebrates to nanoparticles. ${ }^{3}$ Nanosilver particles can be found in wastewater and no purification method was yet determined to completely eliminate the nanosilver particles. ${ }^{5}$ In 1977 , Smith and Carson determined that approximately $150,000 \mathrm{~kg}$ of silver enters the aquatic system every year from industry and those numbers have doubled since then. ${ }^{6}$ Bioaccumulation of silver in the tissues of marine organisms such as oysters, gastropods, planktonic crustaceans and algae has been observed in previous studies. ${ }^{5}$ The purpose of the present study is to determine the effect of nanosilver particles on the phagocytic competence of blue mussels (Mytilus edulis) under a realistic salinity gradient in respect to the St. Lawrence Estuary.

\section{Materials and Methods}

\section{Animals and exposure conditions}

Blue mussels were collected from the South shore of the St. Lawrence Estuary, in Mitis Bay $\left(48^{\circ} 40^{\prime} \mathrm{N}, 68^{\circ} 00^{\prime} \mathrm{W}\right)$. All the collected animals had a shell length measuring between 45 to 65 $\mathrm{mm}$ and were measured using a Vernier caliper. In the laboratory, the mussels were randomly divided into three groups and transferred into three separate aquariums that received constant salt water supplies and were left there for 7 days for acclimation. After acclimation, an initial sacrifice of 15 organisms was performed to determine the initial immune response of the blue mussels.

After the acclimation period, the aquarium system was closed off. One aquarium was kept as a reference tank for the rest of the experiment while the other two were used to simulate different salinities gradient (that can be found in the St. Lawrence Estuary) and organisms of these respective tanks were exposed to different concentrations (2-3 $\mu \mathrm{g} \mathrm{L} \mathrm{L}^{-1}$ and $4-5 \mu \mathrm{g}$ $\mathrm{L}^{-1}$ ) of silver nanoparticles. The water of each tank was manually changed every other day and the mussels were fed using specialized food (Shelfish Diet ${ }^{\circledR} 1800$, Reed mariculture). The tanks were left at room temperature throughout the experiment. Inside the reference aquarium, a salinity level of 15 practical salinity units PSU (moderate brackish water) could be found and no silver nanoparticles were added for the entire duration of the study. For the second aquarium, the salinity was the same as the reference tank (15 PSU) and approximately $4-5 \mu \mathrm{g} \mathrm{L}^{-1}$ of silver nanoparticles were added in the water at each water change. Finally, for the third aquarium, the salinity level was 21 PSU (heavy brackish water) and the mussels were exposed to $2-3 \mu \mathrm{g} \mathrm{L^{-1 }}$ of silver nanoparticles. Two additional sacrifices $(n=15)$ were made; after 14 days and 28 days of in vivo exposure to the nanosilver particles. The mean size $(21.43 \pm 4.06 \mathrm{~nm})$ of the silver nanoparticles used in this study was determined using a Zetasizer (Dynamic Light Scatter instrument).

\section{Hemocyte collection, determination of cell number and viability}

At each sacrifice, hemocytes were collected from the adductor muscle of 15 organisms from each aquarium using a $23 \mathrm{G}$ needle and a $3 \mathrm{~mL}$ syringe.

Cellularity and viability were both determined at each sacrifice by flow cytometry. In summary, $100 \mu \mathrm{L}$ of propidium iodide stock solution $\left(10 \mu \mathrm{L} / \mathrm{mL}^{-1}\right)$ (Sigma Chemical Company) was added to $50 \mu \mathrm{L}$ of the cell suspensions right before flow cytometric acquisition was performed.

\section{Phagocytosis}

For phagocytosis, hemocytes were mixed with yellow-green latex Fluospheres (Molecular Probes Inc., Eugene, Or, USA), diameter $1.2 \mu \mathrm{m}$, at a ratio of 1:100 (hemo-
Correspondence: Michel Fournier, Institut National de la Recherche Scientifique-InstitutArmand-Frappier (INRS-IAF), 531 boul. des Prairies, Laval, Québec, Canada H7V 1B7.

E-mail: michel.fournier@iaf.inrs.ca

Key words: blue mussel, Mytilus edulis, silver nanoparticles, immunotoxicity.

Conference presentation: ECOBIM meeting, 2014 May, Brest, France

This work is licensed under a Creative Commons Attribution NonCommercial 3.0 License (CC BYNC 3.0).

CC Copyright C. Côté et al., 2014

Licensee PAGEPress, Italy

Journal of Xenobiotics 2014; 4:4896

doi:10.4081/xeno.2014.4896

cytes:beads) in microplates. ${ }^{7}$ After the required incubation time of $18 \mathrm{~h}$ in the dark at room temperature $\left(20^{\circ} \mathrm{C}\right)$, the microplates were drained using the inversion method and the cells were resuspended and fixed with $0.5 \%$ formaldehyde. The samples were then read by a flow cytometer (BD Accuri ${ }^{\mathrm{TM}} \mathrm{C} 6$, Becton Dickinson, San Jose, CA, USA). The hemocyte populations were defined based on their forward (FSC) and right angle scatter (SSC) properties. ${ }^{7}$ Phagocytosis was expressed in percentage of phagocytic activity (1 bead or more) and in percentage of phagocytic efficiency ( 3 beads or more).

\section{Statistical analysis}

The effect of silver nanoparticles was expressed as mean \pm SD and were assessed using an ANOVA followed by a Tukey's multiple comparison tests $(\mathrm{P} \leq 0.05)$ using RStudio (s version 2.15.1).

\section{Results}

Total Ag concentration was determined at $\mathrm{T} 0$, T14 and T28 in mussels tissues. Ag accumulation was observed in mussels receiving AgNPS treatment whereas no accumulation was observed in the control. At T28, we observed an increase of around $400 \%$ in mussels tissues from the second aquarium (freshwater) and around 200\% from the third aquarium (brackish water). These results clearly demonstrate that AgNPs exposed mussels have accumulated silver during the exposition (K. Lemarchand, personal communication, 2014).

\section{Viability and cellularity}

No significant differences in the cell number or the viability could be seen during the experiment between the different groups. 

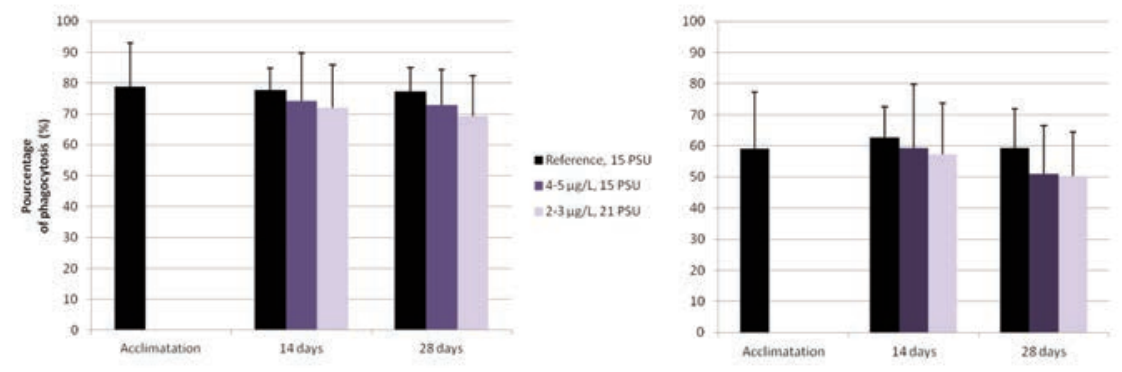

Figure 1. Phagocytic activity (1 bead and more) and phagocytic efficiency ( 3 beads and more) of blue mussel after 7 days of acclimation as well as after 14 and 28 days of exposure to different salinities and concentrations of silver nanoparticules.

\section{Phagocytosis}

The results are presented in Figure 1. No significant differences in the phagocytic capacity and the phagocytic efficiency of the blue mussels were noted between the different groups throughout this experiment. When comparing the phagocytic activity and efficiency, no differences were observed as between the two different sacrifices; after 14 and 28 days of exposure to nanosilver.

\section{Discussion and Conclusions}

Toxicity of silver nanoparticles in many fresh water invertebrate species is now well documented in literature. .,3,5 $^{1,5}$ Therefore, the lack of significant impact of silver nanoparticles during the experiment can most likely be explained by the small concentration of nanoparticles used during the study. The goal of this experiment was to recreate a model with realistic conditions that can be found in the St. Lawrence Estuary and for that reason the quantities used were very small (the maximum concentration being 4-5 $\left.\mu \mathrm{g} \mathrm{L}^{-1}\right)$. Other studies show that when used at higher doses $\left(0.1 \mathrm{mg} \mathrm{L}^{-1}\right)$ nanosilver has a significant toxicity on species like Daphnia magna and can cause significant damages to the organisms. ${ }^{1}$ In addition, other studies showed that the toxicity of silver nanoparticles are lessened when the entire animal is exposed compared to the effect seen when the exposure is done in cell cultures. ${ }^{3}$ Nanosilver, along with other nanoparticles with low Zeta potential, will likely forms aggregates in salinity conditions. It follows that mussels were perhaps not exposed to nanosilver aggregates (i.e. not bioavailable) in these conditions. More research is needed and nanosilver characterization and silver tissue loading should be included to confirm that exposure to silver nanoparticles actually took place.

\section{References}

1. Gaiser KB, Biswas A, Rosenkranz P, Jepson AM, Lead RJ, Stone V, et al. Effects of silver and cerium dioxide micro- and nano-sized particles on Daphnia magna. J Environ Monit 2011;13:1227-35.

2. British Standards. Terminology for nanomaterials. Publicly Available Specification (PAS) 136. London: British Standards Institute; 2007.

3. De Lima R, Seabra BA, Duran N. Silver nanoparticles: a brief review of cytotoxicity and genotoxicity of chemically and biogenically synthesized nanoparticles. J Appl Toxicol 2012;32:867:79.

4. Lorenz C, Windler L, von Goetz N, Lehmann RP, Schuppler M, Hungerbühler $\mathrm{K}$, et al. Characterization of silver release from commercially available functional (nano)textiles. Chemosphere 2012;89: 817-24.

5. Wijnhoven SWP, Peijnenburg WJGM, Heberts CA, Hagens WI, Oomen AG, Heugens EHW, et al. Nano-silver a review of available data and knowledge gaps in human and environmental risk assessment. Nanotoxicol 2009;3:109-38.

6. Ahmed M, Karns M, Goodson M, Rowe J, Hussain SM, Schlager JJ, et al. DNA damage response to different surface chemistry of silver nanoparticles in mammalian cells. Toxicol Appl Pharmacol 2008;233: 404-10.

7. Smith I, Carson B. Trace metals in the environment. Vol. 2. Silver. Ann Arbor: Science Publishers; 1977. pp 469.

8. Brousseau P, Pellerin J, Morin Y, Cyr D, Blakley B, Boermans H, et al. Flow cytometry as a tool to monitor the disturbance of phagocytosis in the clam Mya arenaria hemocytes following in vitro exposure to heavy metals. Toxicology 2000;142:145-56. 